17

1

6

7

\title{
Critical Water Coverage during Forsterite Carbonation in Thin Water Films: Activating Dissolution and Mass Transport
}

\section{${ }^{1}$ Département ArGEnCo/Géophysique appliquée, Urban and Environmental Engineering,} University of Liège, Liège, 4000, Belgium

${ }^{2}$ Physical and Computational Sciences Directorate, Pacific Northwest National Laboratory, Richland, WA 99354, United States

${ }^{3}$ Earth and Biological Sciences Directorate, Pacific Northwest National Laboratory, Richland, WA 99354, United States

${ }^{4}$ Energy and Environment Directorate, Pacific Northwest National Laboratory, Richland, WA 99354, United States

\section{Corresponding Author}

*John S. Loring; john.loring@pnnl.gov

This file contains 13 Pages, 7 Figures, and 0 Tables.

5




\section{In Situ High Pressure Infrared Spectroscopic Titrations}

Infrared (IR) spectra were collected using a Bruker Vertex 80V spectrometer equipped with an air-cooled source, deuterated tri-glycine sulfate (DTGS) detector, and housed in an environmental chamber thermostated to $25 \pm 0.2{ }^{\circ} \mathrm{C}$. The high-pressure optical cell holds a volume of $62.2 \mathrm{~mL}$ and is jacketed for temperature control by a circulating water bath. Temperature is monitored by a high-pressure, K-type thermocouple that is positioned within the main fluid cavity of the cell and that was calibrated using ice and boiling water. Cell pressure is monitored by a pressure transducer that was calibrated against a NIST-traceable standard gauge. The transmission IR optics consist of cylindrical $\mathrm{ZnSe}$ windows and a pathlength of $\sim 4 \mathrm{~cm}$. The internal reflection ambient conditions before obtaining its mass. The forsterite sample on the microscope slide was inserted into the IR cell, and an additional $0.1 \mathrm{ml}$ of a $\sim 5 \mathrm{~g} / 1$ forsterite suspension in isopropanol was pipetted onto the internal reflection element and dried with flowing nitrogen to form an ATR overlayer. Samples were further dried at $50{ }^{\circ} \mathrm{C}$ within the IR cell, first under flow of dry $\mathrm{CO}_{2}$ at 2 bar for 30 minutes, then under vacuum $\left(10^{-3}\right.$ Torr $)$ for another 30 minutes. After pressurization with $\mathrm{CO}_{2}$, a tubing loop with a calibrated volume of $1.81 \mathrm{uL}$ was used to meter water into the cell to increase fluid relative humidity $(\mathrm{RH})$ stepwise. A reaction time of 135 minutes was used between $\mathrm{H}_{2} \mathrm{O}$ additions. ${ }^{1-3}$ 
50 follow reactivity towards carbonation. ATR-IR spectra were corrected for distortions ${ }^{4,5}$ by first

51 converting to optical constant spectra using the method of Bertie et al ${ }^{6,7}$, followed by calculating

52 absorbance spectra from these optical constants for a hypothetical $1 \mu \mathrm{m}$ pathlength transmission

53 cell using the Fresnel equations. ${ }^{8,9}$ Selected portions of corrected ATR-IR spectra were processed

54 with a multivariate curve resolution-alternating least squares (MCR-ALS) chemometrics analysis

55 that uses a non-negativity constraint in both spectral and concentration space. ${ }^{10-12}$

\section{Determination of $\mathbf{n}$ of CPE for Equivalent Circuit Analysis of EIS Results}

57 Constant phase elements (CPEs) have parameters $\mathrm{T}$ and $\mathrm{n}$. When $\mathrm{n}=1$, the CPE is a perfect

58 capacitor, and when $\mathrm{n}=0$, it is a resistor. Values of $\mathrm{n}$ slightly less than 1 are often required in

59 modeling. This is believed to be due to a distribution of time constants associated with an

60

61

62

63

64

67

68 interfacial process around an ideal value because of surface imperfections or roughness. ${ }^{13}$ CPEs with $\mathrm{n}$ slightly less than one manifest in Nyquist plots as depressed or flattened semicircles. In an effort to reduce the degrees of freedom in our modeling, the parameter $n$ of CPE is fixed in the equivalent circuits in Figure 3b. This value of $\mathrm{n}$ is determined by first performing fits of the EIS results from experiments EIS_Exp1_CO $\mathrm{CO}_{2}$ and EIS_Exp2_ $\mathrm{CO}_{2}$ to the equivalent circuits in Figure $3 \mathrm{~b}$ with $\mathrm{n}$ as a variable. The values of $\mathrm{n}$ determined from these fits are then averaged, while only including data with a relative error of less than $0.1 \%$. The average value of $\mathrm{n}$ was calculated to be 0.968 with a standard deviation of 0.006 . 


\section{Potential of Mean Force Calculations}

Potential of mean force calculations (PMF) were performed to determine the free energy

71 landscape of a $\mathrm{Mg}^{2+}$ either adsorbing on the forsterite surface from the fluid phase or diffusing

72 across the surface. In this approach, separate calculations are performed at multiple points along

73 a reaction coordinate with the position of the ion/molecule of interest constrained along the

74 reaction coordinate. The free energy difference between initial position $h_{0}$ and position $h$ is then

75 obtained by integrating the ensemble average of the force along the reaction coordinate, $f$ :

76

$$
\Delta A(h)=\int_{h_{0}}^{h}\langle f(h)\rangle \mathrm{d} h
$$

In the first series of PMF calculations $\left(\mathrm{Mg}^{2+}\right.$ adsorption on the forsterite surface), the

78

79

80

81

82

83

84

85

86

87 normal to the surface, $z$, was used as the reaction coordinate, meaning that $\mathrm{Mg}^{2+}$ was constrained in the $z$ direction but free to move in the $x$ and $y$ directions, and that the force $f_{\mathrm{z}}$ was used in the thermodynamic integration. In the second series of PMF calculations $\left(\mathrm{Mg}^{2+}\right.$ diffusion along the surface, specifically, along the grooves formed by the rows of surface $\mathrm{Mg}$ atoms), the direction parallel to the rows of surface $\mathrm{Mg}$ atoms, $y$, was used as the reaction coordinate, meaning that $\mathrm{Mg}^{2+}$ was constrained in the $y$ direction but free to move in the $x$ and $z$ directions, and that the force $f_{y}$ was used in the thermodynamic integration. In both series of PMF calculations, data points were obtained at $0.2-\AA$ intervals, and the individual PMF calculations were ran for $400 \mathrm{ps}$ following a 50 ps equilibration period. 


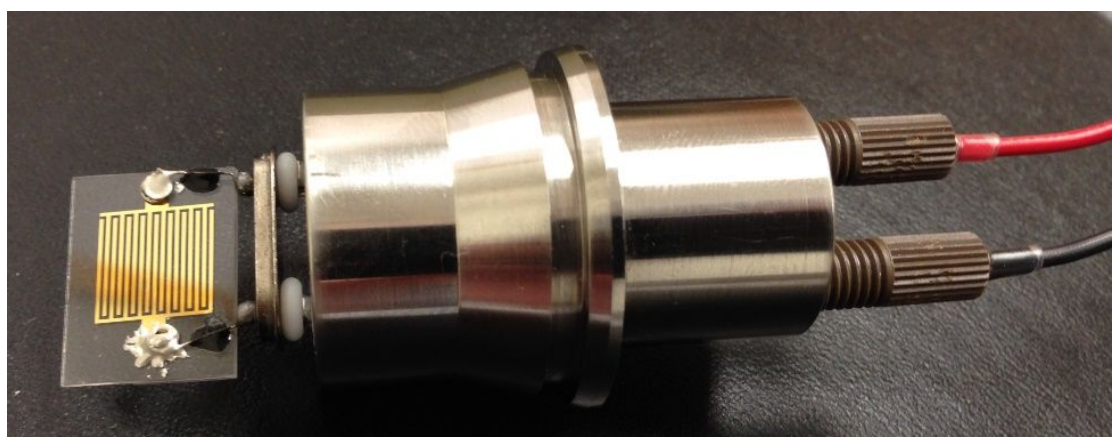

99

Figure S1. Electrical impedance electrode attached to a front cleanout plug of the high-pressure IR titration cell that has been adapted with electrical feedthroughs. This electrode is an interdigitated design comprised of $300 \mu \mathrm{m}$ gold wires printed on a quartz substrate. The spacing between the wires was $400 \mu \mathrm{m}$, and the

103 overall electrode dimensions were about $1 \mathrm{~cm}$ by $1 \mathrm{~cm}$. 

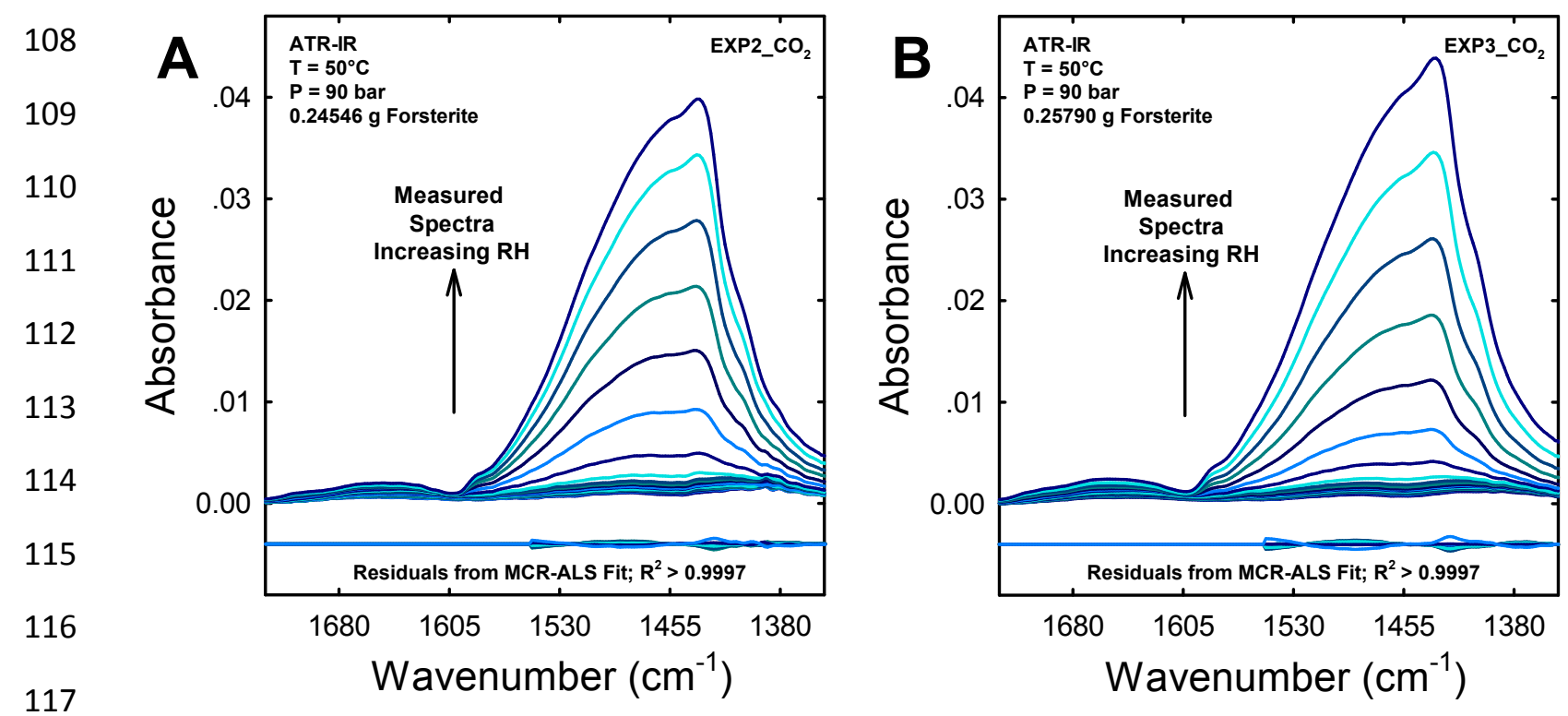

Figure S2. ATR-IR spectra as a function of RH at an increment of $\sim 5 \%$ from $\sim 5 \%$ to $\sim 85 \%$ RH from IR titrations (Exp2_ $\mathrm{CO}_{2}$ and Exp3 $\mathrm{CO}_{2}, \mathrm{~A}$ and $\mathrm{B}$, respectively) of forsterite with $\mathrm{H}_{2} \mathrm{O}$ in $\mathrm{scCO}_{2}$ at $50{ }^{\circ} \mathrm{C}$ and 90 bar. Two-component MCR-ALS fits accounted for better than $99.97 \%$ of the variance, as demonstrated by the small residuals shown offset and below the measured spectra. See also Figure 1 in the main text. 

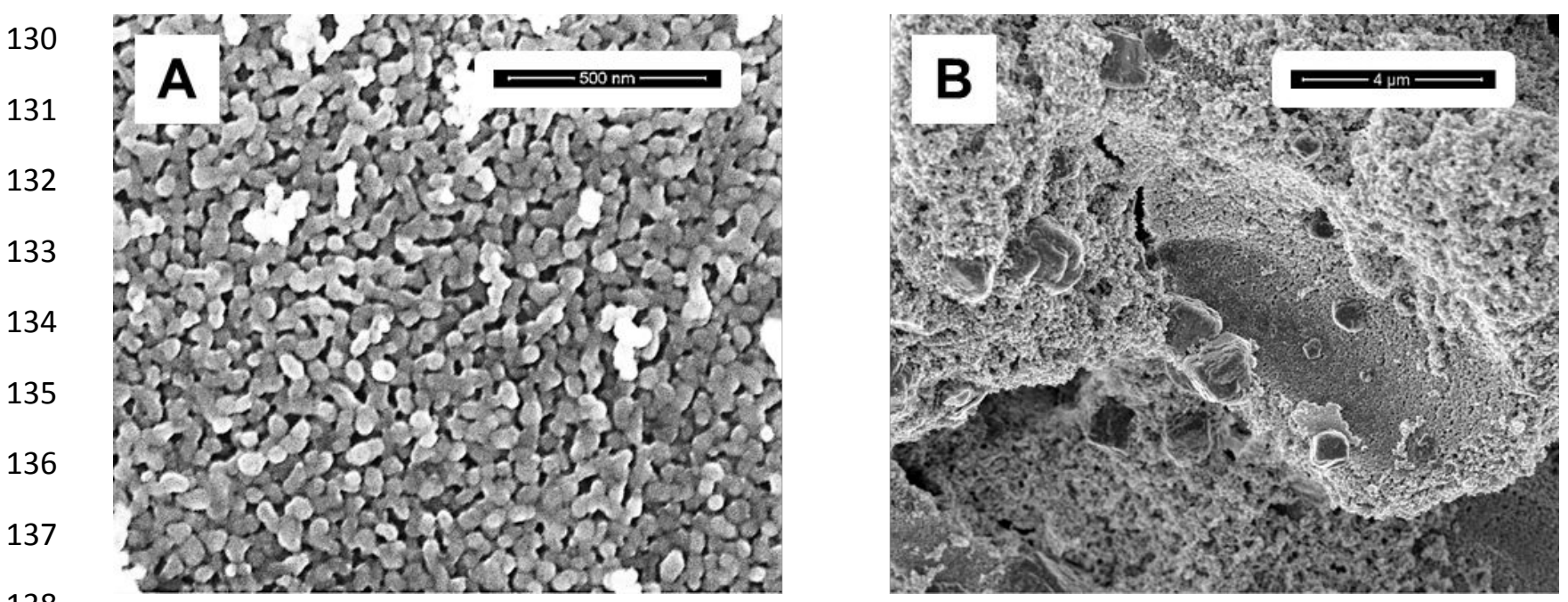

Figure S3. (A) SEM micrograph of unreacted synthetic forsterite used in this study. (B) Micrograph of 142 postreacted forsterite from an IR titration in wet $\mathrm{scCO}_{2}$ at $50{ }^{\circ} \mathrm{C}$ and 90 bar showing precipitated magnesite 143 particles. 


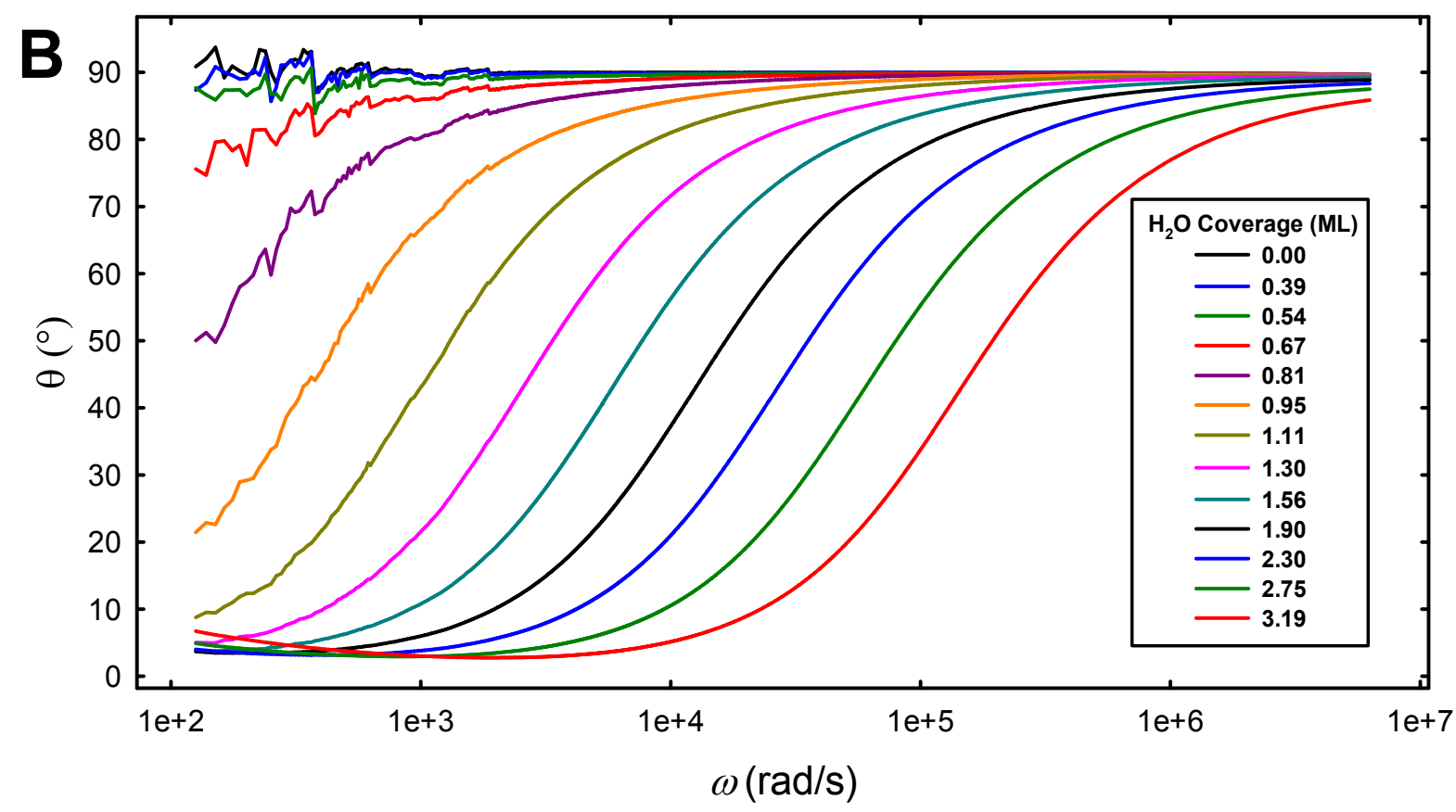

Figure S5. Bode plots of results from EIS_Exp2_ $\mathrm{CO}_{2}$ collected during a titration of forsterite with $\mathrm{H}_{2} \mathrm{O}$ in $\mathrm{scCO}_{2}$ at $50{ }^{\circ} \mathrm{C}$ and 90 bar. The magnitude $\left|Z^{*}\right|$ and phase shift $\theta$ as a function of frequency are shown in (A) and (B), respectively, for $\mathrm{H}_{2} \mathrm{O}$ coverages from 0.00 to 3.19 monolayers. At low $\mathrm{H}_{2} \mathrm{O}$ coverages, the forsterite $/ \mathrm{H}_{2} \mathrm{O}$ film $/ \mathrm{scCO}_{2}$ demonstrates a CPE behavior ( $\approx 90$ degrees) over the entire measured frequency range. With increasing $\mathrm{H}_{2} \mathrm{O}$ coverage, the system shows frequency dispersion associated with surface capacitance distribution towards the higher frequencies. 


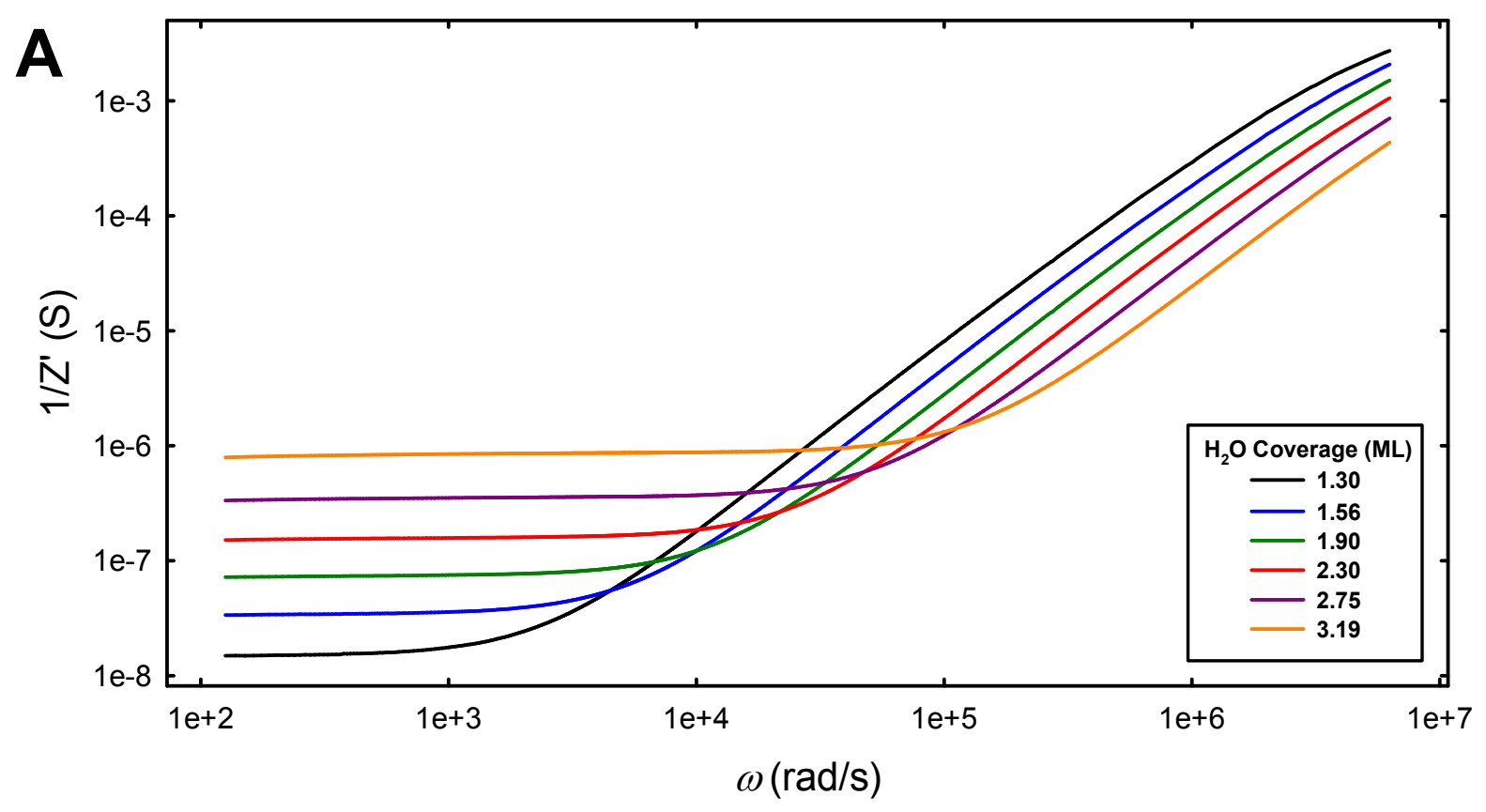

227

228

229

230

231

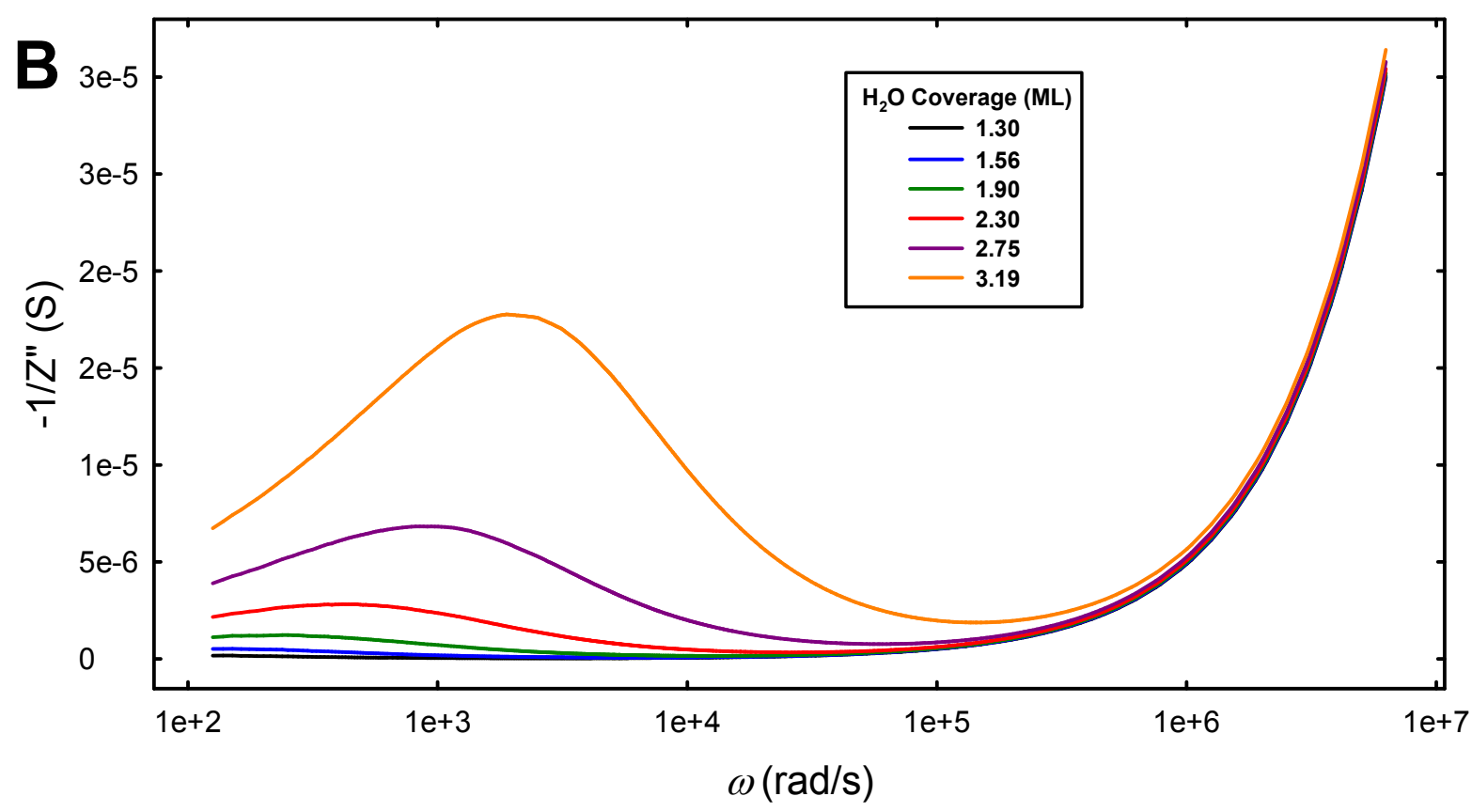

Figure S6. Plots of (A) 1/Z', conductive, and (B) 1/Z”, capacitive component versus frequency from increasing charge carriers), the forsterite surface becomes more conductive at lower frequencies, resulting in a surface polarization mainly controlled by diffusion mechanism. 


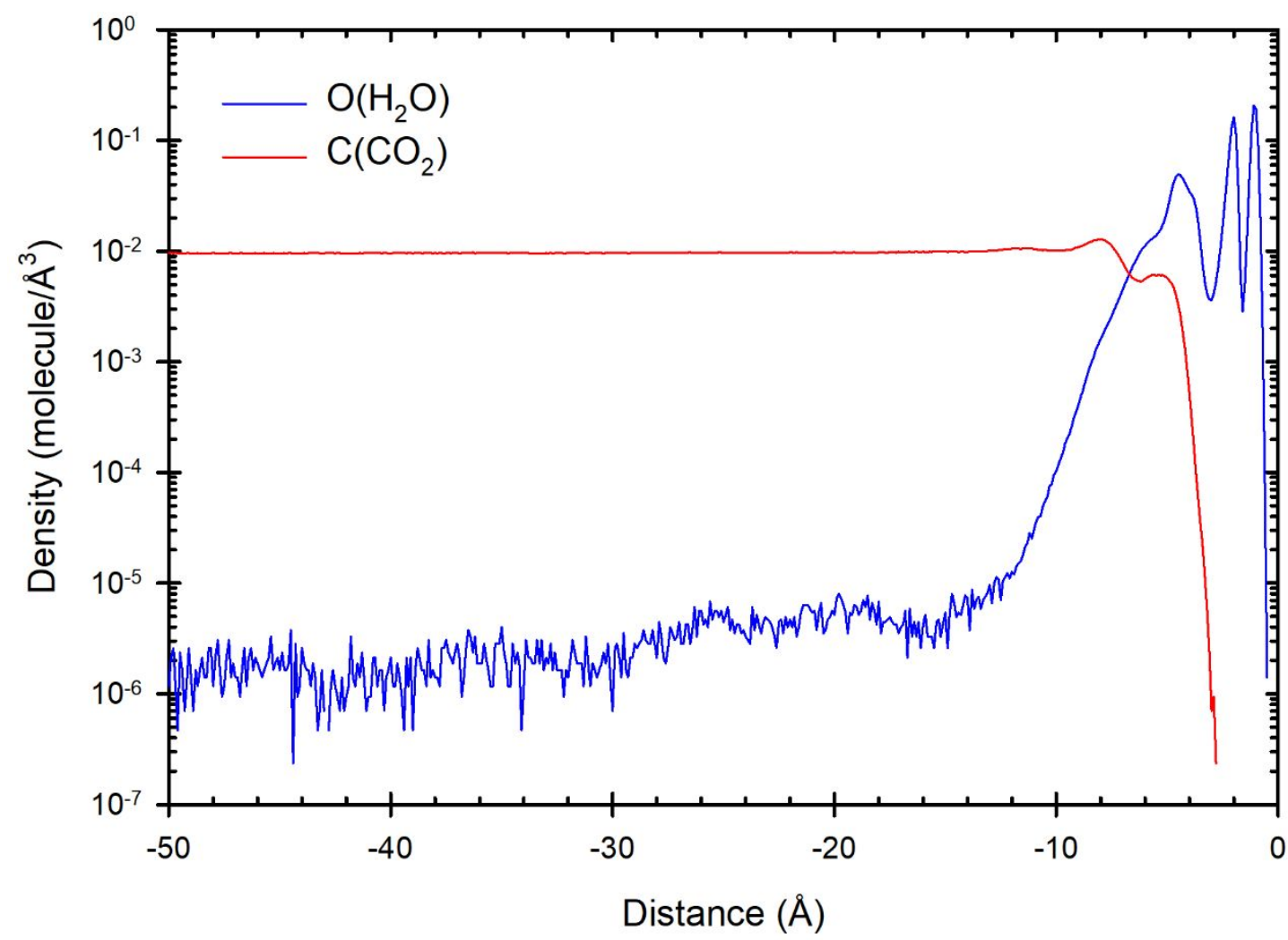

248 Figure $\mathbf{S 7} . \mathrm{O}\left(\mathrm{H}_{2} \mathrm{O}\right)$ and $\mathrm{C}\left(\mathrm{CO}_{2}\right)$ density profiles as a function of distance from the forsterite $(010)$ surface 249 (zero of distance is defined by the average position of the topmost $\mathrm{Mg}$ atoms) as obtained from the 250 simulation with 3.0 monolayers of water adsorbed on the forsterite surface. The reader is referred to Kerisit 251 et al. $(2012)^{14}$ for a discussion of the variations of the $\mathrm{O}\left(\mathrm{H}_{2} \mathrm{O}\right)$ and $\mathrm{C}\left(\mathrm{CO}_{2}\right)$ density profiles across the whole 252 system. 


\section{References}

255

256

257

258

259

260

261

262

263

264

265

266

267

268

269

270

271

272

273

274

(1)

Bowers, G. M.; Schaef, H. T.; Loring, J. S.; Hoyt, D. W.; Burton, S. D.; Walter, E. D.; Kirkpatrick, R. J. Role of cations in $\mathrm{CO}_{2}$ adsorption, dynamics, and hydration in smectite clays under in situ supercritical $\mathrm{CO}_{2}$ conditions, J. Phys. Chem. C 2017, 121, 577-592.

(2) Loring, J. S.; Bacon, D. H.; Springer, R. D.; Anderko, A.; Gopinath, S.; Yonkofski, C. M.; Thompson, C. J.; McGrail, B. P.; Rosso, K. M.; Schaef, H. T. Water solubility at saturation for $\mathrm{CO}_{2}-\mathrm{CH}_{4}$ mixtures at 323.2 K and 9.000 MPa, J. Chem. Eng. Data 2017, 62, 1608-1614.

(3) Thompson, C. J.; Martin, P. F.; Chen, J.; Benezeth, P.; Schaef, H. T.; Rosso, K. M.; Felmy, A. R.; Loring, J. S. Automated high-pressure titration system with in situ infrared spectroscopic detection, Rev. Sci. Instrum. 2014, 85.

(4) Boulet-Audet, M.; Buffeteau, T.; Boudreault, S.; Daugey, N.; Pézolet, M. Quantitative determination of band distortions in diamond attenuated total reflectance infrared spectra, J. Phys. Chem. B 2010, 114, 8255-8261.

(5) Harrick, N. J. Internal Reflection Spectroscopy; John Wiley \& Sons: New York, 1967.

(6) Bertie, J. E.; Eysel, H. H. Infrared intensities of liquids I: Determination of infrared optical and dielectric constants by FT-IR using the CIRCLE ATR cell, Appl. Spectrosc. 1985, 39, 392-401.

(7) Bertie, J. E.; Zhang, S. L.; Manji, R. Infrared intensities of liquids X: Accuracy of current methods of obtaining optical constants from multiple attenuated total reflection measurements using the CIRCLE cell, Appl. Spectrosc. 1992, 46, 1660-1665.

(8) Ohta, K.; Ishida, H. Matrix formalism for calculation of electric field intensity of light in stratified multilayered films, Appl. Opt. 1990, 29, 1952-1959. 
(9) Loring, J. S.; Land, D. P. Theoretical determination of parameters for optimum surface 276 specificity in overlayer attenuated-total-reflection infrared spectroscopy, Appl. Opt. 1998, 37, 3515-

2773526.

278

(10) Gorzsás, A. MCR-ALS GUI V4c, Open source MATLAB script from the Vibrational

279 Spectroscopy Core Facility, Umeå University, Umeå Sweden 2017,

280 http://www.kbc.umu.se/english/visp/download-visp/.

281

(11) de Juan, A.; Tauler, R. Multivariate curve resolution (MCR) from 2000: Progress in

282 concepts and applications, Crit. Rev. Anal. Chem. 2006, 36, 163-176.

283

(12) Yeşilbaş, M.; Boily, J.-F. Thin ice films at mineral surfaces, J. Phys. Chem. Lett. 2016, 7,

$284 \quad 2849-2855$.

285

(13) Orazem, M. E.; Tribollet, B. Electrochemical impedance spectroscopy; John Wiley \& Sons, 2862017.

287

(14) Kerisit, S.; Weare, J. H.; Felmy, A. R. Structure and dynamics of forsterite-scCO $\mathrm{SCO}_{2} / \mathrm{H}_{2} \mathrm{O}$

288 interfaces as a function of water content, Geochim. Cosmochim. Acta 2012, 84, 137-151.

289 